\title{
Investigation of the probabilistic low cycle fatigue design curves at stress cycling
}

\author{
Z. Bazaras*, R. Cesnavicius**, J. Ilgakojyte-Bazariene***, R. Kersys**** \\ *Kaunas University of Technology, Studentu 56, 51424 Kaunas, Lithuania, E-mail: zilvinas.bazaras@ktu.lt \\ **Kaunas University of Technology, Studentu 56, 51424 Kaunas, Lithuania, E-mail: ramunas.cesnavicius@ktu.lt \\ ***Kaunas University of Technology, Studentu 56, 51424 Kaunas, Lithuania, E-mail: jurga.ilgakojyte@ktu.lt \\ ****Kaunas University of Technology, Studentu 56, 51424 Kaunas, Lithuania, E-mail: robertas.kersys@ktu.lt \\ cross $^{\text {ref }}$ http://dx.doi.org/10.5755/j01.mech.23.2.14358
}

\section{Introduction}

In working conditions some equipment's components are affected by high loads, which results in elastic plastic cyclic deformation. These type of loads may cause fatigue damage over time and results in crack propagation and fracture of the equipment. Due cyclic overloads, the cyclic varying stresses exceeds the proportional limit of the materials and after thousands cycles the fatigue crack appears which will result in part's failure with hardly predictable corollary $[1,2]$.

Aiming to improve the reliability and safety of the structures, the probabilistic methods for low cycle fatigue data, are applied in many manuscripts $[3,4]$. These methods are based on statistically collected cyclic loading data and their probabilistic characteristics.

Probabilistic methods have been used for the assessment of statistical and fatigue damage properties [5].

Considerable contribution to the investigation of probabilistic methods, probabilistic substantiation of allowable stresses and strength safety and proposed calculation in the static and cyclic strength are used by many investigators [6-8].

The aim of this paper is to design the probabilistic estimation curves of low cycle fatigue. Also, a comparison of the probabilistic curves with the experimental data have been made [9].

\section{Experimental setup for monotonic and low cycle loading}

Experimental setup consists of $50 \mathrm{kN}$ testing machine YMM-5 and an electronic part, which is designed to record the stress-strain diagrams, cycles and contol the gear reversal. The $4 \mathrm{~mm} / \mathrm{min}$ speed of deformation was used for tensile experiments. The cycle frequency of 4-10 cycles/min and $20 \mathrm{~mm} / \mathrm{min}$ speed of deformation were used for low cycle tension-compression testing. The force and deformation meassurement range warries not more than $\pm 5 \%$. GOST 25.502-79 standard was used for metal fatigue tests, whereas GOST 22015-76 - for probabilistic calculation of matallic parts. All the testing set-up with mechanical and electrical schemes is described in literature [10].

Experimental monotonic tension and low cycle tension-compression were carried out under ambient temperature. The specimens were tested under symmetric loading $(R=-1)$ and experimental data was registered up to of the crack initiation.
The specimens of circular cross-section with $d=10 \mathrm{~mm}$ were used for low cycle fatigue tension-compression experiments. The specimens were made of grade steel $15 \mathrm{Cr} 2 \mathrm{MoVA}$ and 45 rods according the dimensions presented in the Fig. 1.

For determination of mechanical properties the material for monotinic tension specimens was taken from the part of cyclic test specimens which has not been subjected to plastic deformation. The specimens of circular cross-section with $d=5 \mathrm{~mm}$ and length $5 d$ were used for these tests.

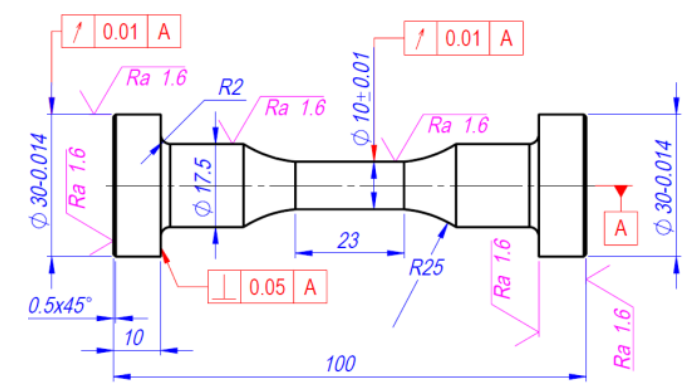

Fig. 1 Low cycle test specimen

In this paper, the low cycle fatigue tests were carried out under stress limited loading with two materials: cyclically softening steel 15Cr2MoVA (Fig. 2, a) and cyclically stable steel 45 (Fig. 2, b). The chemical composition and mechanical properties of the tested materials are presented in Table 1 and Table 2. As it seen from the Table 2, the materials are very ductile, especially 15Cr2MoVA $(\psi=80 \%)$ [7-9]. The monotonous tension curve has plasticity of yielding, whereas $15 \mathrm{Cr} 2 \mathrm{MoVA}$ doesn't have [9].

Table 1

Chemical compositions of tested materials

\begin{tabular}{|l|c|c|c|c|c|c|}
\hline \multirow{4}{*}{$\begin{array}{l}\text { Steel } \\
\text { 15Cr2MoVA }\end{array}$} & $\mathrm{C}$ & $\mathrm{Si}$ & $\mathrm{Mn}$ & $\mathrm{Cr}$ & $\mathrm{Ni}$ & $\mathrm{Mo}$ \\
\cline { 2 - 7 } & 0.18 & 0.27 & 0.43 & 2.7 & 0.17 & 0.67 \\
\cline { 2 - 7 } & $\mathrm{V}$ & $\mathrm{S}$ & $\mathrm{P}$ & $\mathrm{Mg}$ & $\mathrm{Cu}$ & $\mathrm{Al}$ \\
\cline { 2 - 7 } & 0.30 & 0.019 & 0.013 & - & - & - \\
\hline \multirow{5}{*}{ Steel 45 } & $\mathrm{C}$ & $\mathrm{Si}$ & $\mathrm{Mn}$ & $\mathrm{Cr}$ & $\mathrm{Ni}$ & $\mathrm{Mo}$ \\
\cline { 2 - 7 } & 0.46 & 0.28 & 0.63 & 0.18 & 0.22 & - \\
\cline { 2 - 7 } & $\mathrm{V}$ & $\mathrm{S}$ & $\mathrm{P}$ & $\mathrm{Mg}$ & $\mathrm{Cu}$ & $\mathrm{Al}$ \\
\cline { 2 - 7 } & - & 0.038 & 0.035 & - & - & - \\
\hline
\end{tabular}

Three stress levels at stress cycling are evenly distributed over the range. Number of the tested specimens at each loading level are presented in the Table 3. In the 
middle levels number of the specimens were increased because the increased scatter was observed in the intermediate zone.

Table 2

Mechanical properties of tested materials

\begin{tabular}{|c|c|c|c|c|c|c|}
\hline \multirow{2}{*}{ Grade } & $\sigma_{p r}$ & $\sigma_{0.2}$ & $\sigma_{u}$ & $\mathrm{~S}_{\mathrm{k}}$ & $\mathrm{e}_{\mathrm{pr}}$ & $\psi$ \\
\hline & \multicolumn{4}{|c|}{$\mathrm{MPa}$} & \multicolumn{2}{|c|}{$\%$} \\
\hline Steel 15Cr2MoVA & 280 & 400 & 580 & 1560 & 0.2 & 80 \\
\hline Steel 45 & 340 & 340 & 800 & 1150 & 0.26 & 39 \\
\hline
\end{tabular}

Table 3

Statistical low cycle testing program

\begin{tabular}{|c|c|c|}
\hline \multirow{2}{*}{ Grade } & \multicolumn{2}{|c|}{ Stress limited loading } \\
\cline { 2 - 3 } & $\begin{array}{c}\text { Loading } \\
\text { level }\end{array}$ & Number of specimen \\
\hline \multirow{4}{*}{ Steel 15Cr2MoVA } & 1.00 & 20 \\
\cline { 2 - 3 } & 1.12 & 40 \\
\cline { 2 - 3 } Steel 45 & 1.25 & 20 \\
\hline \multirow{3}{*}{} & 1.00 & 20 \\
\cline { 2 - 3 } & 1.25 & 40 \\
\cline { 2 - 3 } & 1.50 & 20 \\
\hline
\end{tabular}

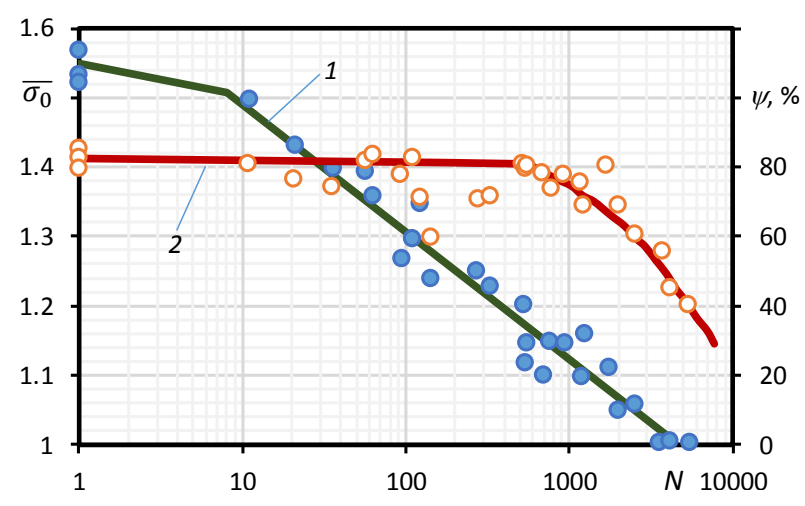

a

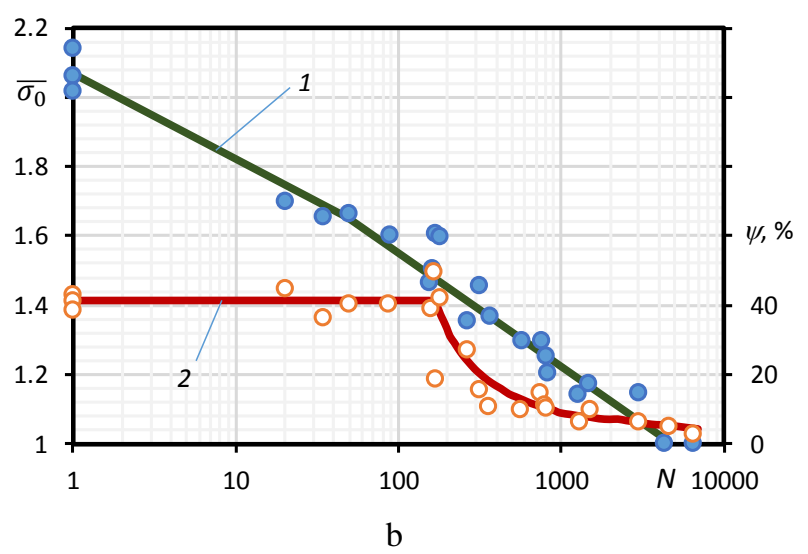

Fig. 2 Low cycle fatigue curves (1) and reduction of the area of cross-section $\psi(2)$ under stress limited loading of the materials: a - steel 15Cr2MoVA; b - steel 45

\section{Mathematical analysis of probabilistic low cycle fatigue design curves}

The purpose of stress limited tests is to define material fracture characteristics at elastic-plastic cyclic loading. For the assessment of a material strength the analytical relation between the static damage and accumulative plastic deformation was introduced in the Eq. (1) [1]:

$$
\sigma_{a} N_{p}^{m}=\sigma_{u} N_{u}^{m}=\text { const }
$$

where $\sigma_{a}$ is stress amplitude; $N_{p}$ is fatigue durability; $N_{u}$ is number of cycles to fracture; $m$ is a constant.

For analytical calculation, the fatigue curve of stress limited loading can be expressed as follow [11]:

$$
e_{0}=\frac{1}{N^{m_{\sigma}}} \ln \frac{100}{100-\psi}+\frac{\sigma_{-1}}{E}
$$

where $e_{0}$ - initial strain; $m_{\sigma}$ - a constant dependent of mechanical properties of the material.

Under stress limited loading the part fractures due to quasi-static damage $d_{K}$, caused by the accumulated plastic strain $\bar{e}_{p k}$, and due to fatigue damage $d_{N}$, resulted by the cyclic plastic strain, which is characterized by the hysteresis loop's width $\bar{\delta}_{k}$. The total damage $d$ may be written (up to fracture, $d=1$ ) [10]:

$$
d=d_{K}^{q}+d_{N}^{l},
$$

where $d_{K}^{q}, d_{N}^{l}$ - quasi-static and fatigue damage; $q$ and $l$ - material constants [9-10].

Fatigue damage is calculated using the following Eq. (4):

$$
d_{N}=\frac{\sum_{1}^{k} \bar{\delta}_{k}}{\sum_{1}^{k_{0}} \bar{\delta}_{k}}
$$

where $\sum_{1}^{k} \bar{\delta}_{k}$ - fatigue damage accumulated during $k$ loading semi-cycles, $\sum_{1}^{k_{0}} \bar{\delta}_{k}$ - fatigue damage accumulated up to crack initiation (when $d_{K}=0$ ).

Quasi-static damage is calculated using the following Eq. (5):

$$
d_{K}=\frac{\bar{e}_{p k}}{\bar{e}_{u_{2}}},
$$

where $\bar{e}_{p k}$ - accumulated plastic strain after $k$ loading semicycles; $\bar{e}_{u_{2}}$ - maximum uniform strain under monotonic loading which corresponds $\sigma_{u}$.

The accumulated plastic strain after $k$ loading semi-cycles, can be expressed as follows:

$$
\begin{aligned}
& \bar{e}_{p k}=\bar{e}_{0}-\bar{\sigma}_{0}-\left(\bar{e}_{0}-\frac{\bar{S}_{T}}{2}\right) \sum_{1}^{k}\left[\frac{A_{1}}{2}-(-1)^{k} \frac{A_{1}}{2}\right] \times \\
& \times \exp \beta(k-1)+\left(\bar{e}_{0}-\frac{\bar{S}_{T}}{2}\right) \sum_{1}^{k}\left[\frac{A_{2}}{2}+(-1)^{k} \frac{A_{2}}{2}\right] \times \\
& \times \exp \beta(k-1) .
\end{aligned}
$$


For cyclically softening and stable materials the accumulated plastic strain can be expressed as follows:

$$
\begin{aligned}
& \bar{e}_{p k}=\bar{e}_{0}-\bar{\sigma}_{0}-\left(\bar{e}_{0}-\frac{\bar{S}_{T}}{2}\right) \sum_{1}^{k}\left[\frac{A_{1}}{2}-(-1)^{k} \frac{A_{2}}{2}\right] \frac{1}{k^{0}}+ \\
& +\left(\bar{e}_{0}-\frac{\bar{S}_{T}}{2}\right) \sum_{1}^{k}\left[\frac{A_{2}}{2}+(-1)^{k} \frac{A_{1}}{2}\right] \frac{1}{k^{0}},
\end{aligned}
$$

where $A_{1}, A_{2}, \beta, \alpha$ are material constants.

For strain cycling, the Eq. 4 can be written as:

$$
d_{N}=\frac{\bar{\delta}_{k}}{\sum_{1}^{k_{0}} \bar{\delta}_{k}}
$$
pressed as:

For $k$ loading semi-cycles the Eq. 4 can be ex-

$$
d_{N}=\frac{\sum_{1}^{k} \bar{\delta}_{k}}{\sum_{1}^{k_{0}} \bar{\delta}_{k}},
$$

where $\bar{\delta}_{k}$ - width of the hysteresis loop of initial semi-cycle.

When $k=k_{0}$ the accumulated fatigue damage is equal $d_{N}=1$.

Durability of low cycle stress limited loading till the fatigue fracture can be expressed:

$$
\frac{\sum_{1}^{k} \bar{\delta}_{k}}{\sum_{1}^{k_{0}} \overline{\delta_{k}}}=1
$$

Quasi-static damage can be calculated applying Eq. 5 and for quasi-static and intermediate mode $d_{K}<1$. For quasi-static mode $d_{N} \ll d_{K}$ and for practical calculations it is assumed that $d_{K}=1$, then:

$$
\bar{e}_{p k}=\bar{e}_{u}=\ln \frac{100}{100-\psi} .
$$

For the intermediate mode quasi-static and fatigue damages can be calculated from Eqs. (3)-(5):

$$
\left(\frac{\sum_{1}^{k_{0}} \bar{\delta}_{k}}{\sum_{1}^{k_{N}} \bar{\delta}_{k}}\right)^{q}+\left(\frac{\bar{e}_{p k_{0}}}{e_{p k_{0}}^{a v}}\right)^{l}=1,
$$

for tested materials it is assumed that $q=l$.

Calculated curve of low cycle stress limited loading only fatigue damage is evaluated then can be written:

$$
\frac{\bar{\delta}_{1}}{\sum_{1}^{k_{01}} \bar{\delta}_{k}}+\frac{\bar{\delta}_{2}}{\sum_{1}^{k_{02}} \bar{\delta}_{k}}+\ldots+\frac{\bar{\delta}_{k_{0}}}{\sum_{1}^{k_{0 k}} \bar{\delta}_{k}}=1
$$

where $\sum_{1}^{k_{01}} \bar{\delta}_{k}$ - accumulated fatigue damage till crack initiation which is characterized by the hysteresis loop's width $\bar{\delta}_{1} ; \sum_{1}^{k_{02}} \bar{\delta}_{k}$ - accumulated fatigue damage till crack initiation which is characterized by the hysteresis loop's width $\bar{\delta}_{2}$, etc.

The fatigue curve in logarithmic coordinates $\lg \bar{\delta}_{a v}-\lg k_{0}$ has a shape of the straight line, then:

$$
\bar{\delta}_{a v}=C_{2} k_{0}^{-\alpha_{2}},
$$

where $\bar{\delta}_{a v}=\frac{1}{k_{0}} \sum_{1}^{k_{0}} \bar{\delta}_{k}$ then:

$$
\sum_{1}^{k_{0}} \bar{\delta}_{k}=C_{2} k_{0}^{1-\alpha_{2}}
$$

where $\bar{\delta}_{a v}$ - average value of the hysteresis loop's width; $k_{0}$ - semi-cycle of initial loading; $\alpha_{2}$ and $C_{2}$ - material constants.

If the expressions $\lg \bar{\varepsilon}-\lg k_{0}, \bar{\varepsilon} k_{0}^{\alpha_{1}}=C_{3}$ are used, where $C_{3}=2^{\alpha_{1}} C_{1}$, then:

$$
k_{0}=\frac{C_{3}^{\frac{1}{\alpha_{1}}}}{\bar{\varepsilon}^{\frac{1}{\alpha_{1}}}} .
$$

Substituting Eq. (16) into (15) it is obtained $\sum_{1}^{k_{0}} \bar{\delta}_{k}=C_{2} \frac{C_{3}^{\frac{1-\alpha_{2}}{\alpha_{1}}}}{\bar{\varepsilon}^{\frac{1-\alpha_{2}}{\alpha_{1}}}}$.

By introducing the $\frac{1-\alpha_{2}}{\alpha_{1}}=\alpha_{3}$, the dependence can be written:

$$
\sum_{1}^{k_{0}} \bar{\delta}_{k}=C_{2} \frac{C_{3}^{\alpha_{3}}}{\bar{\varepsilon}^{\alpha_{3}}}
$$

The analytical curves as only fatigue damage were calculated applying the following Eq. (18):

$$
\frac{\bar{\delta}_{1} \bar{\varepsilon}_{1}^{\alpha_{3}}}{C_{2} C_{3}^{\alpha_{3}}}+\frac{\bar{\delta}_{2} \bar{\varepsilon}_{2}^{\alpha_{3}}}{C_{2} C_{3}^{\alpha_{3}}}+\ldots+\frac{\bar{\delta}_{k_{C}} \bar{\varepsilon}_{k_{C}}^{\alpha_{3}}}{C_{2} C_{3}^{\alpha_{3}}}=1
$$

For calculation of the monotonous tension, the linear or step-function approximation can be applied. Using the step-function approximation, the Eq. (18) will look: 


$$
\begin{aligned}
& A_{1}\left(\bar{\sigma}_{0}^{\frac{1}{m_{0}}}-\frac{\bar{S}_{T}}{2}\right)\left\{F(1)\left[2 \bar{\sigma}_{0}+A_{1}\left(\bar{\sigma}_{0}^{\frac{1}{m_{0}}}-\frac{\bar{S}_{T}}{2}\right) F(1)\right]^{\alpha_{3}}+F(3)\left[2 \bar{\sigma}_{0}+A_{1}\left(\bar{\sigma}_{0}^{\frac{1}{m_{0}}}-\frac{\bar{S}_{T}}{2}\right) F(3)\right]^{\alpha_{3}}+\ldots+F\left(2 N_{0}+1\right)\right\} \times \\
& \left.\times\left[2 \bar{\sigma}_{0}+A_{1}\left(\bar{\sigma}_{0}^{\frac{1}{m_{0}}}-\frac{\bar{S}_{T}}{2}\right) F\left(2 N_{0}+1\right)\right]^{\alpha_{3}}\right\}+A_{2}\left(\bar{\sigma}_{0}^{\frac{1}{m_{0}}}-\frac{\bar{S}_{T}}{2}\right)\left\{F(2)\left[2 \bar{\sigma}_{0}+A_{2}\left(\bar{\sigma}_{0}^{\frac{1}{m_{0}}}-\frac{\bar{S}_{T}}{2}\right) F(2)\right]^{\alpha_{3}}+\right. \\
& \left.+F(4)\left[2 \bar{\sigma}_{0}+A_{2}\left(\bar{\sigma}_{0}^{\frac{1}{m_{0}}}-\frac{\bar{S}_{T}}{2}\right) F(4)\right]^{\alpha_{3}}+\ldots+F\left(2 N_{0}\right)\left[2 \bar{\sigma}_{0}+A_{2}\left(\bar{\sigma}_{0}^{\frac{1}{m_{0}}}-\frac{\bar{S}_{T}}{2}\right) F\left(2 N_{0}\right)\right]^{\alpha_{3}}\right\}=C_{2} C_{3}^{\alpha_{3}},
\end{aligned}
$$

where $N_{0}=\frac{k_{0}}{2} ; m_{0}$ - material intensification coefficient for step-function approximation. terials:

For cyclically hardening, softening and stable ma-

$$
\begin{aligned}
& F(k)=\exp \beta(k-1) ; \\
& F(k)=\frac{1}{k^{0}} ; \\
& F(k)=1,
\end{aligned}
$$

where $\alpha=\beta=0$.

For cyclically stable materials:

$$
\frac{\sum_{1}^{k} \bar{\delta}_{k}}{\sum_{1}^{k_{0}} \bar{\delta}_{k}}=\frac{k}{k_{0}} \text {. }
$$

Then sum of relative cyclic deformations (Eq. 13) can be replaced by sum of relative durability, then:

$$
\sum_{i} \frac{k_{i}}{k_{0_{i}}}=1
$$

Then $\bar{\delta}_{k}=\bar{\delta}_{a v}=$ const and substituting into Eqs. (14), (24) becomes:

$$
\sum_{i} k_{i} \bar{\delta}_{k}^{\frac{1}{\alpha_{2}}}=C_{2}^{\frac{1}{\alpha_{2}}}
$$

or

$$
\left(\sum_{i} k_{i} \bar{\delta}_{k}^{\frac{1}{\alpha_{2}}}\right)^{\alpha_{2}}=\left(\bar{\delta}_{1}^{\frac{1}{\alpha_{2}}}+\bar{\delta}^{\frac{1}{\alpha_{2}}}+\ldots+\bar{\delta}_{k}^{\frac{1}{\alpha_{2}}}\right)^{\alpha_{2}}=C_{2} .
$$
it can be:

For the step-function approximation using Eq. 26

$$
\bar{\sigma}_{0}=\left\{\frac{C_{2}}{\left[\left(A_{1}^{\frac{1}{\alpha_{2}}}+A_{2}^{\frac{1}{\alpha_{2}}}\right) N\right]^{\alpha_{2}}}-\frac{\bar{S}_{T}}{2}\right\}^{m_{0}} .
$$

\section{Verification of low cycle fatigue design curves}

The probabilistic low cycle design curves were calculated for steel 15Cr2MoVA and 45 using the Eqs. (19) and (27). The parameters for calculation of these curves are presented in Table 4.

Table 4

Probabilistic values of the cyclic characteristics

\begin{tabular}{|c|c|c|c|c|c|c|c|c|}
\hline \multirow{2}{*}{$\begin{array}{c}\text { Parame- } \\
\text { ters }\end{array}$} & \multicolumn{7}{|c|}{ Probability, \% } \\
\cline { 2 - 8 } & 1 & 10 & 30 & 50 & 70 & 90 & 99 \\
\hline$A_{1}$ & 0.23 & 0.87 & 1.32 & 1.60 & 1.94 & 2.40 & 3.04 \\
\hline$A_{2}$ & 0.30 & 0.94 & 1.34 & 1.64 & 2.00 & 2.43 & 3.06 \\
\hline $\bar{S}_{T}$ & 1.15 & 1.20 & 1.25 & 1.28 & 1.30 & 1.35 & 1.40 \\
\hline$m_{0}$ & 0.15 & 0.17 & 0.19 & 0.21 & 0.23 & 0.26 & 0.30 \\
\hline$\beta \times 10^{-3}$ & 0.04 & 0.16 & 0.42 & 0.85 & 1.80 & 4.80 & 19.0 \\
\hline$C \times 10^{-4}$ & 1.10 & 3.00 & 4.80 & 7.40 & 11.0 & 21.0 & 50.0 \\
\hline \multicolumn{7}{|c|}{ Steel 45} \\
\hline$A_{1}$ & 0.60 & 0.76 & 0.87 & 0.95 & 1.04 & 1.15 & 1.29 \\
\hline$A_{2}$ & 0.64 & 0.80 & 0.89 & 0.96 & 1.05 & 1.16 & 1.30 \\
\hline $\bar{S}_{T}$ & 0.92 & 1.02 & 1.07 & 1.11 & 1.15 & 1.21 & 1.29 \\
\hline$m_{0}$ & 0.14 & 0.16 & 0.18 & 0.19 & 0.20 & 0.22 & 0.25 \\
\hline
\end{tabular}

The probabilistic constants of the low cycle strain limited loading of steel $15 \mathrm{Cr} 2 \mathrm{MoVA}$ and 45 were used for calculation are shown in Table 5.

Probabilistic constants of $C_{2}$ and $\alpha_{2}$ were determined using logarithmic coordinates $\lg \bar{\delta}_{a v}-\lg k_{0}$ (Fig. 3). Width of the hysteresis loop was calculated using Eq. (28):

$$
\bar{\delta}_{1}=A_{1}\left(\bar{e}_{0}-\frac{\bar{S}_{T}}{2}\right) .
$$

The probabilistic curves of low cycle stress limited loading for steel 15Cr2MoVA was calculated using Eq. (19) and for steel 45 - using Eq. (27). The parameter of cyclical deformation was determined by Eq. (29):

$$
\beta=C\left(\bar{e}_{0}-\frac{\bar{S}_{T}}{2}\right) .
$$




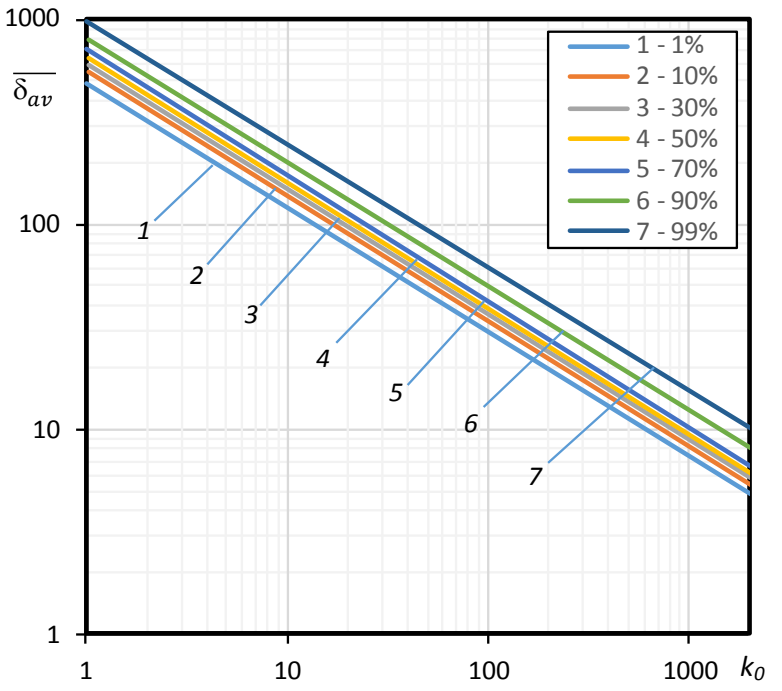

a

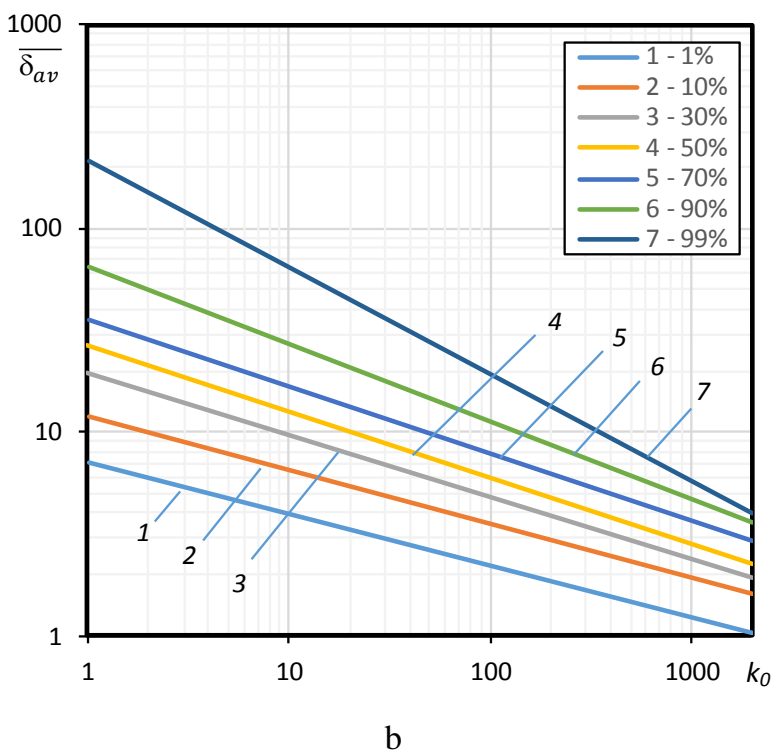

Fig. 3 Probabilistic calculation of hysteresis loop dependence on semi-cycles of stress limited curves: a - steel 15Cr2MoVA; b - steel 45

Fig. 4, a shows the probabilistic curves of stress limited loading where curve of $99 \%$ probability shows lowest lifetime, whereas $1 \%$ - highest. This is due to high reduction of $e_{p r}$, which was used in this type of calculation and also high reduction of deformation parameters compare to reduction of the area of cross-section $\psi$. This type of calculation showed contrariety with experimental data. To eliminate this type of discrepancy, mean arithmetic parameters of cyclic deformation was used for the next step.

For determination of the probabilistic curves, the probabilistic coefficients' $C_{2}, C_{3}, \alpha_{3}$ values were used (Table 5). Using this type of calculation methodology, the low cycle curves got appropriate order, i. e. curve of $1 \%$ showed lowest lifetime, whereas 99\% - highest (Fig. 4, b).

The probabilistic calculation of low cycle stress limited curves for steel 15Cr2MoVA is shown in Fig. 4, a, whereas for steel 45 in Fig. 5, a. The comparison of calculation and experimental data of these graphs is shown in
Fig. 4, b, and Fig. 5, b, respectively.

Low cycle stress limited calculation for anisotropic materials showed a satisfactory agreement with experimental data when loading level is $\bar{\sigma}_{0}=1$. When loading level $\bar{\sigma}_{0}>1$, the calculation is not adequate, because of quasi-static damage which gives error, but doesn't count to fatigue lifetime calculation.

Table 5

Probabilistic constants

\begin{tabular}{|c|c|c|c|c|c|c|c|}
\hline \multirow{2}{*}{$\begin{array}{c}\text { Parame- } \\
\text { ters }\end{array}$} & \multicolumn{7}{|c|}{ Probability, \% } \\
\cline { 2 - 8 } & 1 & 10 & 30 & 50 & 70 & 90 & 99 \\
\hline \multicolumn{8}{|c|}{ Steel 15Cr2MoVA } \\
\hline$C_{1}$ & 205 & 215 & 235 & 240 & 260 & 285 & 350 \\
\hline$\alpha_{1}$ & 0.48 & 0.49 & 0.49 & 0.50 & 0.50 & 0.50 & 0.50 \\
\hline$C_{2}$ & 500 & 535 & 590 & 630 & 680 & 790 & 940 \\
\hline$\alpha_{2}$ & 0.53 & 0.53 & 0.53 & 0.54 & 0.54 & 0.54 & 0.54 \\
\hline$C_{3}$ & 286 & 302 & 330 & 339 & 368 & 403 & 494 \\
\hline$\alpha_{3}$ & 0.98 & 0.96 & 0.96 & 0.92 & 0.92 & 0.92 & 0.92 \\
\hline \multicolumn{7}{|c|}{ Steel 45 } \\
\hline$C_{2}$ & 7.60 & 12.0 & 19.8 & 27.5 & 37.0 & 67.0 & 230 \\
\hline$\alpha_{2}$ & 0.24 & 0.25 & 0.28 & 0.31 & 0.32 & 0.38 & 0.52 \\
\hline
\end{tabular}

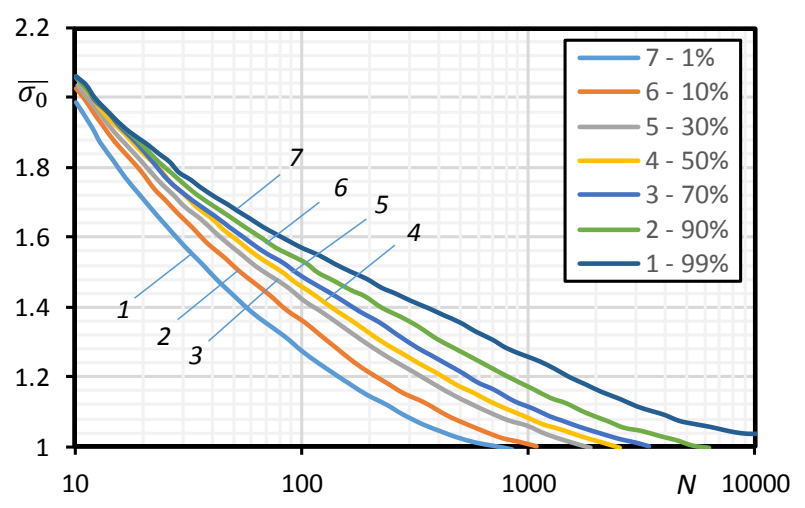

a

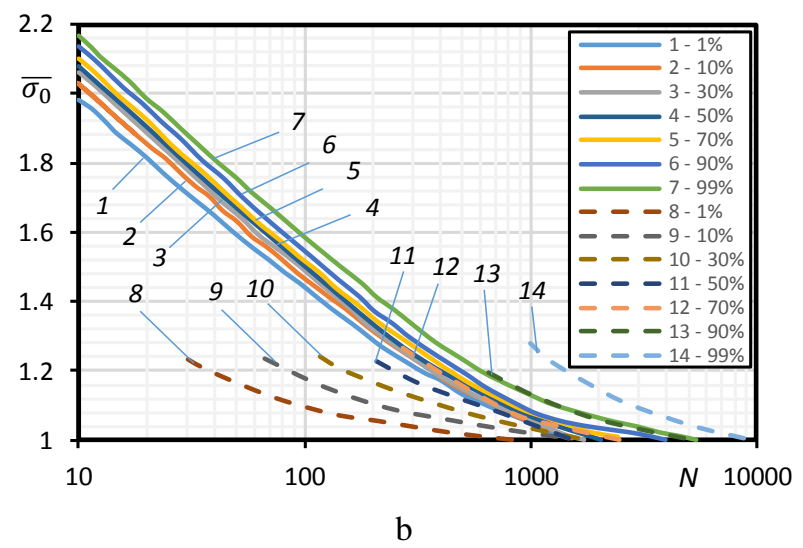

Fig. 4 Probabilistic calculation of low cycle stress limited curves for steel 15Cr2MoVA ( $1-7$ analytical probability $1 \%-99 \% ; 8-14$ experimental probability $1 \%$ - 99\%): a - calculation; b - comparison with experiment 

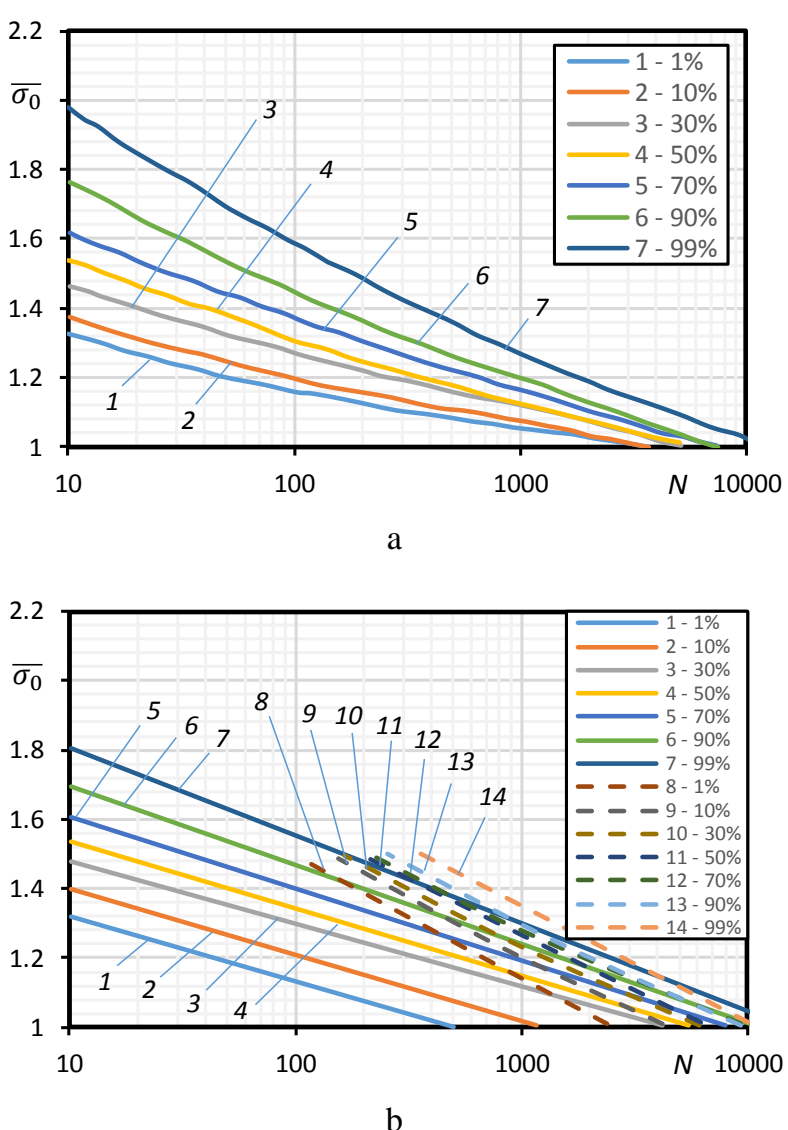

Fig. 5 Probabilistic calculation of low cycle stress limited curves for steel 45 ( $1-7$ analytical probability $1 \%$ $99 \% ; 8-14$ experimental probability $1 \%-99 \%)$ : $\mathrm{a}$ - calculation; $\mathrm{b}$ - comparison with experiment

\section{Conclusions}

The following conclusions can be drawn from this study:

1. Design curves of fracture probability for steels $15 \mathrm{Cr} 2 \mathrm{MoVA}$ and 45 at low cycle stress limited loading were calculated and the probabilistic curves were compared with experimental ones.

2. Low cycle stress limited calculation for anisotropic materials showed a satisfactory agreement with experimental data when loading level is $\bar{\sigma}_{0}=1$. When loading level $\bar{\sigma}_{0}>1$, the calculation is not adequate, because of quasi-static damage which gives error, but doesn't count to fatigue lifetime calculation.

\section{References}

1. Benham, P., Ford, H. 1961. Low endurance fatigue of mild steel and on aluminium alloy, J. of Mechanical Eng. Sci. 3(2): 119-132.

2. Iida, K., Inoue, H. 1973. Life distribution and design curve in low cycle fatigue, Papers of Ship Research Institute, Tokyo, No. 45, 39 p.

3. Beretta, S., Foletti, S. 2014. A simple format for failure probability under LCF and its application to a complex component, 20th European Conference on Fracture (ECF20), Procedia Materials Science 3: 2098-2103.

4. Zhu, S.-P.; Huang, H.-Z.; Ontiveros, V.; He, L.-P.; Modarres, M. 2012. Probabilistic low cycle fatigue life prediction using an energy-based damage parameter and accounting for model uncertainty, International Journal of Damage Mechanics 21: 1128-1153. http://dx.doi.org/10.1177/1056789511429836.

5. Schmitz, S.; Seibel, T.; Beck, T.; Rollmann, G.; Krause, R.; Gottschalk, H. 2013. A probabilistic model for LCF, Computational Materials Science 79: 584-590.

6. Haldar, A.; Mahadevan, S. 2000. Probability, Reliability and Statistical Methods in Engineering Design, New York, John Wiley \& Sons, 305 p.

7. Mahutov, N.A. 2005. Structural durability, resource and tech. safety, Novosibirsk: Nauka, Vol. 1, 494 p. (in Russian).

8. Mahutov, N.A. 2005. Structural Durability, Resource and Tech. Safety, Novosibirsk: Nauka, Vol. 2, 610 p. (in Russian).

9. Bazaras, Z. 2005. Analysis of probabilistic low cycle fatigue design curves at strain cycling, Indian Journal of Engineering \& Material Sciences 2: 411-418.

10. Daunys, M. 2005. Cycle Strength and Durability of Structures, Kaunas: Technologija, 286 p. (in Lithuanian).

11. Lendzer, B. 1962. Low cycle durability calculation of high pressure vessel, Technicheskaja Mechanika 3: 97-113 (in Russian).

Z. Bazaras, R. Cesnavicius, J. Ilgakojyte-Bazariene,
R. Kersys

INVESTIGATION OF THE PROBABILISTIC LOW CYCLE FATIGUE DESIGN CURVES AT STRESS CYCLING

S u m m a r y

This paper presents the investigation of probabilistic calculation of low cycle fatigue curves. The experiment of low cycle fatigue was made and cyclic constants were defined. Based on data obtained, design curves of equal fracture probability $15 \mathrm{Cr} 2 \mathrm{MoVA}$ and 45 at low cycle stress limited loading were drawn. The design curves were compared with experimental data and the conclusions were made. Low cycle stress limited calculation for anisotropic materials showed a satisfactory agreement with experimental data and can be used in lifetime assessment of various power plant facilities.

Keywords: probabilistic calculation, low cycle fatigue.

Received March 10, 2016 Accepted April 14, 2017 